\section{References}

1. Starr A, Edwards ML. Mitral replacement: clinical experience with a ball-valve prosthesis. Ann Surg. 1961;154:726-40.

2. Godje OL, Fischlein T, Adelhard K, Nollert G, Klinner W, Reichart B. Thirty-year results of Starr-Edwards prostheses in the aortic and mitral position. Ann Thorac Surg. 1997;63:613-9.
3. He GW, Grunkemeier GL, Gately HL, Furnary AP, Starr A. Up to thirty-year survival after aortic valve replacement in the small aortic root. Ann Thorac Surg. 1995;59:1056-62.

4. Aludaat C, Gay A, Guetlin A, Nafeh-Bizet C, Bessou JP, Doguet F. Favorable evolution of a 43-year-old Starr-Edwards valve in the tricuspid position. J Heart Valve Dis. 2012;21:679-81.

\title{
A complicated case of Carney complex: Fifth reoperative cardiac surgery for resection of recurrent cardiac myxoma
}

\author{
Manuel Wilbring, MD, ${ }^{\mathrm{a}}$ Stephan Wiedemann, MD, ${ }^{\mathrm{b}}$ Utz Kappert, MD, ${ }^{\mathrm{a}}$ and Klaus Matschke, MD, \\ Dresden, Germany
}

Carney complex is a rare genetic disorder that was first described by Carney and colleagues ${ }^{1}$ in 1985 . It is mainly characterized by cardiac myxoma, spotty pigmentation and endocrine hyperactivity. In approximately $50 \%$ of the affected patients, a heterozygous mutation of the protein kinase A regulatory subunit 1 gene (PRKARIA) can be found. The mutation, which is usually localized on the long arm of chromosome 17 (17q22-q24), is named CC-Type 1. In CC-Type 2, the mutation can be found on chromosome 2 (2p16). The heredity is autosomal dominant with variable penetrance. There exist no clinical differences between genetic carriers and noncarriers. ${ }^{2}$

\section{CLINICAL SUMMARY}

In 2012, a 60-year-old female patient with Carney complex and history of previous 4 cardiac operations for recurrent myxoma was seen for elective echocardiographic control. The previous control by magnetic resonance imaging (MRI) 5 months previously had been unremarkable (Figure 1, A).

In 1988, 1991, 2002, and 2008 she had already undergone cardiac surgery for resection of cardiac myxoma at different localizations. Further clinical signs of Carney complex were recurrent mucosal tumors since her earliest childhood, spotty pigmentation, hirsutism, syndactyly of the toes, kyphosis, hyperthyroidism, and an adenoma of the pituitary gland. The patient also had a history of peripheral arterial

From the Departments of Cardiac Surgery ${ }^{\mathrm{a}}$ and Cardiology, ${ }^{\mathrm{b}}$ University Heart Center Dresden, Dresden, Germany.

Disclosures: Authors have nothing to disclose with regard to commercial support.

Received for publication May 26, 2013; accepted for publication May 31, 2013; available ahead of print July 17, 2013

Address for reprints: Manuel Wilbring, MD, Department of Cardiac Surgery, University Heart Center Dresden, Fetscherstrasse 76, 01307 Dresden, Germany (E-mail: manuel.wilbring@gmail.com).

J Thorac Cardiovasc Surg 2013;146:e22-4

$0022-5223 / \$ 36.00$

Copyright (c) 2013 by The American Association for Thoracic Surgery

http://dx.doi.org/10.1016/j.jtcvs.2013.05.016 embolism and occlusion of superficial femoral artery. As demonstrated in the family tree in Figure 2, the patient was the only one in her family affected by clinical signs of Carney complex. Genetic examination of her family has not been performed to date.

MRI and echocardiography revealed a new intracardiac tumor-formation in the left ventricle affecting the mitral annulus (Figure 1, $A-C$ ). Cardiac surgery was performed through a median sternotomy and with common aortic cannulation. For venous cannulation, a 2-stage cannula was used. The procedure was performed in normothermia. Intraoperatively, the myxoma was resected (Figure 1,D). Because of the involvement of the mitral annulus and the need for radical resection, biologic mitral valve replacement was also performed. The intraoperative and postoperative courses were uneventful. Predischarge echocardiography revealed good prosthetic function. Histopathologic examination identified the tumor as a myxoma. The patient was dismissed from the hospital on postoperative day 6 .

\section{DISCUSSION}

Carney complex is a rare genetic disorder. ${ }^{1,3}$ This patient demonstrated all the typical signs of Carney complex including myxoma, spotty pigmentation, endocrine hyperactivity, and cutaneous tumors. As is typical with complications of cardiac tumors, the patient also had a history of peripheral arterial embolism and occlusion of superficial femoral artery. In contrast with other reported cases, a specific characteristic of the present case was the fifth recurrence of myxoma, each time at a different location. ${ }^{4,5}$ The reported patient is the sole person affected by Carney complex in her family. This might be explained by the variable penetrance of the autosomal dominant genetic disorder. Her fifth reoperative cardiac surgical procedure could be performed without any procedural morbidity, despite strong pericardial adhesions. Worth mentioning is the fact that MRI control 


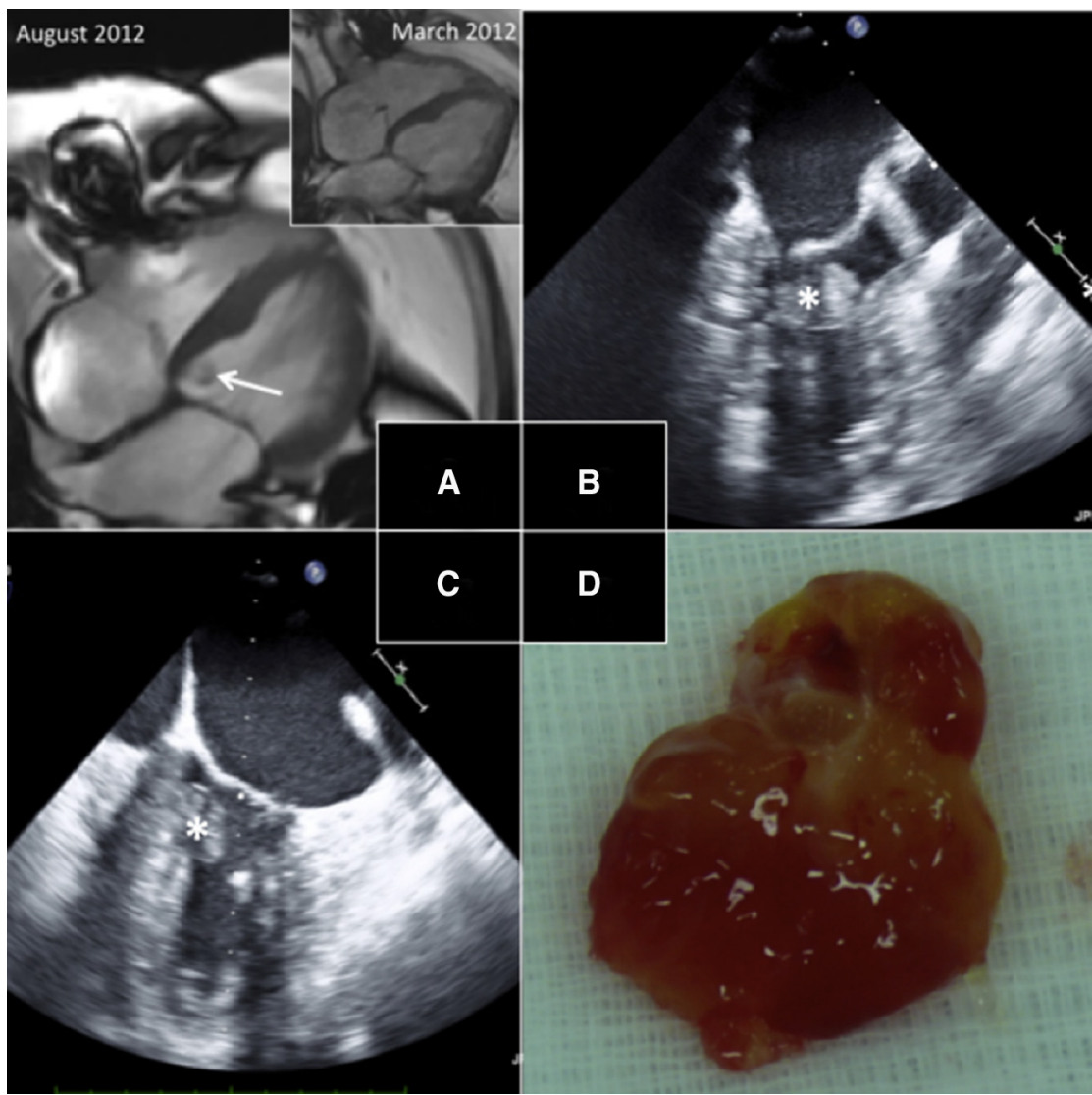

FIGURE 1. A, Magnetic resonance imaging scan of the heart demonstrating left ventricular tumor (arrow) in August 2012. Previous control scan in March 2012 (inset) was unremarkable. B and C, Transesophageal echocardiography revealing the left-ventricular tumor (asterisk). D, Intraoperative photograph of resected specimen.

only 5 months before had been unremarkable, which highlights the need for control examinations at close intervals. Common diagnostic modes, such as clinical examination, electrocardiography, and chest radiography, are inefficient. Further diagnostic modes, such as transesophageal echocardiography or MRI scan, are required. Identification and close monitoring of patients with recurrent myxoma in the context of Carney complex

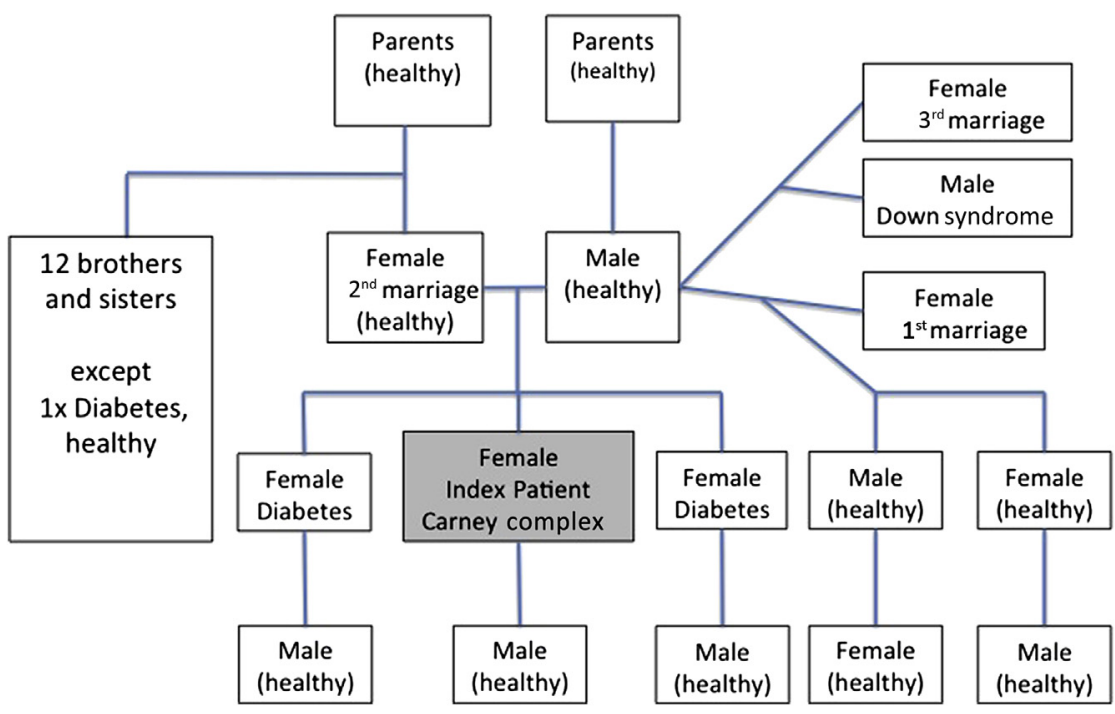

FIGURE 2. Family tree of the patient. 
is of utmost importance to prevent such typical complications of cardiac tumors as stroke or embolism.

\author{
References \\ 1. Carney JA, Gordon H, Carpenter PC, Shenoy BV, Go VL. The complex of \\ myxomas, spotty pigmentation, and endocrine overactivity. Medicine (Baltimore).
} $1985 \mathrm{Jul} ; 64: 270-83$.
2. Sandrini F, Stratakis C. Clinical and molecular genetics of Carney complex. Mol Genet Metab. 2003;78:83-92.

3. Boikos SA, Stratakis CA. Carney complex: the first 20 years. Curr Opin Oncol. 2007;19:24-9.

4. Borkar SS, Kamath SG, Kashyap N, Sagar SC, Rao L, Warrier R, et al. Carney Complex: case report and review. J Cardiothorac Surg. 2011;6:25.

5. Salhab KF, Said SM, Schaff HV. Resection of multiple recurrent cardiac myxomas in an adult man with Carney's complex. Ann Thorac Surg. 2012;93:2071.

\title{
Initial experience of transcatheter aortic valve replacement with the $\mathrm{St}$ Jude Medical Portico valve inserted through the transapical approach
}

\author{
Marina Urena, MD, Daniel Doyle, MD, Josep Rodés-Cabau, MD, and Eric Dumont, MD, Quebec City, \\ Quebec, Canada
}

Video clip is available online.

The St Jude Medical Portico THV (St Jude Medical, Inc, St Paul, Minn) is the first fully resheathable percutaneous valve. We report the feasibility of implantation of the 23-mm St Jude Medical Portico THV by the transapical approach. Despite this encouraging initial experience, future studies are needed to demonstrate the safety and efficacy of this new valve.

\section{CLINICAL SUMMARY}

An 82-year-old woman was referred to our center for aortic valve replacement. She was not considered to be a candidate for surgical aortic valve replacement in the evaluation of the heart team because of severe comorbidities (diabetes, hypertension, anemia, recent myocardial infarction requiring percutaneous intervention with left main drug eluting stent implantation, severe peripheral vascular disease) leading to a predicted risk of perioperative mortality of 7.8 as estimated by Society of Thoracic Surgeons

$\overline{\text { From the Quebec }}$ Heart and Lung Institute, Laval University, Quebec City, Quebec, Canada.

Disclosures: J.R.-C. is a consultant for Edwards Lifesciences, Inc, and St Jude Medical, Inc, and E.D. is a consultant for Edwards Lifesciences Inc. All other authors have nothing to disclose with regard to commercial support.

Portico is a trademark of St Jude Medical, Inc, St Paul, Minn.

Received for publication April 11, 2013; revisions received May 29, 2013; accepted for publication June 6, 2013; available ahead of print July 25, 2013.

Address for reprints: Eric Dumont, MD, Quebec Heart and Lung Institute, Laval University, 2725 Chemin Ste-Foy, G1V 4G5 Quebec City, Quebec, Canada (E-mail:

Eric.Dumont@criucpq.ulaval.ca).

J Thorac Cardiovasc Surg 2013;146:e24-7

$0022-5223 / \$ 36.00$

Copyright (C) 2013 by The American Association for Thoracic Surgery

http://dx.doi.org/10.1016/j.jtcvs.2013.06.005 score. An echocardiographic assessment confirmed a severely calcific aortic stenosis (mean gradient $38 \mathrm{~mm}$ $\mathrm{Hg}$; aortic valve area: $0.65 \mathrm{~cm}^{2}$ ) with normal left ventricular function and an aortic annulus of $19.5 \mathrm{~mm}$. A transcatheter aortic valve implantation procedure with the 23$\mathrm{mm}$ Portico valve through the transapical approach was planned. Signed, informed consent was obtained for the procedure and for this publication.

The procedure was performed in the operating room with general anesthesia and echocardiographic and fluoroscopic guidance with a $\mathrm{C}$-arm radiographic system. A standard transapical approach was carried out, as described previously. ${ }^{1}$ Initially, a 7F sheath was inserted to secure the access site. After a stiff wire was placed in the descending aorta, the $7 \mathrm{~F}$ sheath was replaced by a $14 \mathrm{~F}$ introducer sheath. An aortic valvuloplasty was then performed with an $18-\mathrm{mm}$ balloon, after which the $24 \mathrm{~F}$ (outer diameter) St Jude delivery system with integrated sheath and mounted Portico valve was inserted through the apex and placed at the aortic annulus level on the stiff wire (Figure 1, A). Rapid pacing was not used for valve deployment. The valve was gradually released by rotating the thumbwheel in a clockwise direction with a continuous tension to keep the position of the distal edge of the skirt at the level of the aortic annulus (Figure 1, B). When $80 \%$ of the valve had been released, the positioning was assessed with several angiographic studies (Figure 1, $C$, and Video 1). The valve was recaptured and repositioned to achieve an optimal position, at which time it was fully released (Figure 1, D). Balloon postdilatation with a 23-mm balloon was performed because of initial mild-to-moderate paravalvular aortic regurgitation (PAR). After balloon and sheath removal, once hemostasis was complete, the chest was closed in a standard fashion. The final result showed trivial PAR and correct positioning 